\title{
Assessment of efficacy of Detection of Deep Venous Thrombosis by Magnetic Resonance Imaging: An Observational Study
}

\author{
Shruti Kapoor ${ }^{1}$, V M Kulkarni \\ ${ }^{1}$ PG Student, 2Professor and Head, Department of Radio Diagnosis, Dr D Y Patil Patil Medical College, Hospital and Research \\ Centre, Pimpri Pune. Maharashtra, India
}

Corresponding author: Dr Shruti Kapoor, PG Student, Department of Radio Diagnosis, Dr D Y Patil Patil Medical College, Hospital and Research Centre, Pimpri Pune. Maharashtra, India

DOI: http://dx.doi.org/10.21276/ijcmsr.2018.3.4.14

How to cite this article: Shruti Kapoor, V M Kulkarni. Assessment of efficacy of detection of deep venous thrombosis by magnetic resonance imaging: an observational study. International Journal of Contemporary Medicine Surgery and Radiology. 2018;3(4):D63-D65.

\section{A B S T R A C T}

Introduction: Magnetic resonance imaging (MRI) provides a safe, noninvasive method to examine the brain's macrostructure, microstructure, and some aspects of how the living brain functions. Before 1995 the approach was to image all patients with suspected DVT and to repeat tests 1 week later if results were negative. Hence; we planned the present study to assess the effectiveness of gradient recalled echo MRI in evaluation of deep venous thrombosis.

Material and methods: The present study included assessment of effectiveness of gradient recalled echo MRI in evaluation of deep venous thrombosis. Detailed information regarding the echo MRI findings of all the patients was obtained. Data records were summarized and detailed ultrasound and computed tomography information of the subjects was also obtained. Results: 35 were confirmed on venography and the remaining 15 were confirmed on ultrasound. Sensitivity of MRI was found to be $96 \%$, while specificity of the MRI was found to be $98 \%$. The overall accuracy of MRI was found to be $97 \%$.

Conclusion: Acute deep venous thrombosis cases can be accurately diagnosed by using gradient recalled echo acquisitions with MRI.

Key words: Deep Venous Thrombosis, Magnetic Resonance Imaging

\section{INTRODUCTION}

Magnetic resonance imaging (MRI) uses the body's natural magnetic properties to produce detailed images from any part of the body. MRI provides a harmless, noninvasive method to examine the brain's macrostructure, microstructure, and certain parameters of how the living brain controls. MRI is talented of classifying irregularities that can happen with alcoholism as well as changes that can occur with sobriety and relapse. ${ }^{1-3}$ Deep-vein thrombosis (DVT) has an projected yearly prevalence of 67 per 100000 among the general populations. ${ }^{4}$ Despite adequate therapy, $1 \%$ to $8 \%$ of patients in whom pulmonary embolism develops will die, whereas others will experience long-term complications such as postphlebitic syndrome (40\%) and chronic thromboembolic pulmonary hypertension (4\%). ${ }^{5}$ Although anticoagulant therapy decreases the risk of recurrent thrombosis, the treatment also increases the risk of major hemorrhage. Before 1995 the approach was to image all patients with suspected DVT and to repeat tests 1 week later if results were negative. ${ }^{6-8}$ Hence; the present study was planned to assess the effectiveness of gradient recalled echo MRI in evaluation of deep venous thrombosis.

\section{MATERIAL AND METHODS}

The present study was carried out in the department of radiodiagnosis of the medical institute and it included assessment of effectiveness of gradient recalled echo MRI in evaluation of deep venous thrombosis. Ethical approval was obtained before the starting of the study from the institutional ethical committee. Subjects were informed about the study and the consent for follow up was obtained from all.For the present retrospective study, data records of the 100 patients were evaluated. Detailed information regarding the echo MRI findings of all the patients was obtained. Inclusion criteria included:

- Patients between the age group of 25 to 75 years,

- Patients with negative history of any other systemic illness

- Patients in which, complete data records were available. Data records were summarized and detailed ultrasound and computed tomography information of the subjects was also obtained. Ultrasound was regarded as the reference for the evaluation of thrombus. Clinical follow up of all the subjects was done to determine the accuracy of MRI. Follow up of all the patients was done using hospital records 


\begin{tabular}{|l|c|c|}
\hline $\begin{array}{l}\text { Age- wise groups } \\
\text { (years) }\end{array}$ & $\begin{array}{c}\text { Number of } \\
\text { subjects }\end{array}$ & $\begin{array}{c}\text { Percentage of } \\
\text { subjects }\end{array}$ \\
\hline Less than 30 & 22 & 22 \\
\hline 30 to 50 & 56 & 56 \\
\hline More than 50 & 22 & 22 \\
\hline Total & 100 & 100 \\
\hline \multicolumn{2}{|r|}{ Table-1: Age-wise distribution of subjects } \\
\hline
\end{tabular}

\begin{tabular}{|l|c|c|}
\hline Gender & $\begin{array}{c}\text { Number of } \\
\text { subjects }\end{array}$ & $\begin{array}{c}\text { Percentage of } \\
\text { subjects }\end{array}$ \\
\hline Male & 60 & 60 \\
\hline Female & 40 & 40 \\
\hline Total & 100 & 100 \\
\hline \multicolumn{2}{|c|}{ Table-2: Gender-wise distribution of subjects } \\
\hline
\end{tabular}

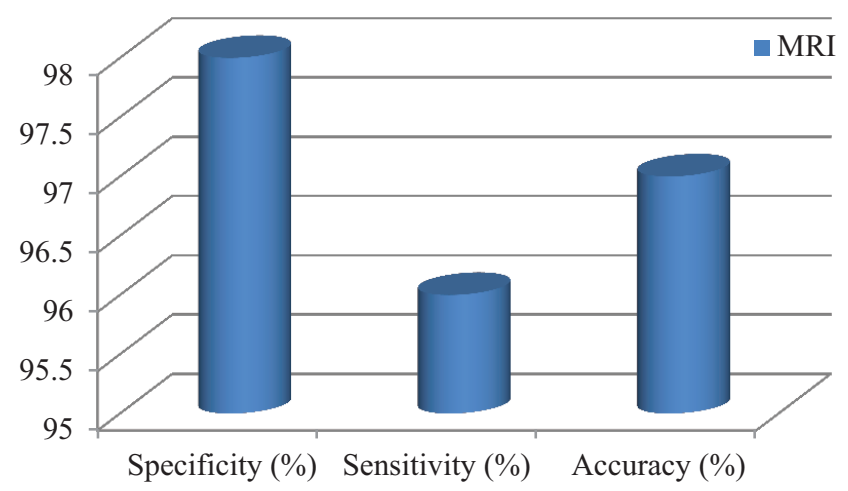

Graph-1: Sensitivity and specificity of confirmed cases of acute deep vein thrombosis $(n=50)$

or telephonic conversation. All MRI were done using 1.5 tesla unit. Gradient images were obtained amongst all the patients. Ultrasound was performed using real time images and linear array transducers with doppler and color flow capacity. Interpretation of the radiographic evaluations was performed by trained single clinician to avoid human error

\section{RESULTS}

Data records of a total of 100 patients were analyzed. Among these patients, 56 percent belonged to the age group of 30 to 50 years (table-1). 22 percent each were less than 30 years of age and more than 50 years of age (table-2). There were 60 males and 40 females in the present study. In 40 cases, acute deep vein thrombosis was present. 35 were confirmed on venography and the remaining 15 were confirmed on ultrasound. Sensitivity of MRI was found to be $96 \%$, while specificity of the MRI was found to be $98 \%$ (figure-1). The overall accuracy of MRI was found to be $97 \%$.

\section{DISCUSSION}

In the present study, data records of a total of 100 patients were analyzed. Among these patients, 56 percent belonged to the age group of 30 to 50 years. 22 percent each were less than 30 years of age and more than 50 years of age. There were 60 males and 40 females in the present study.

In another previous study conducted by Spritzer CE et al, authors assessed effectiveness of gradient recalled echo magnetic resonance imaging in evaluating DVT. They retrospectively reviewed 2016 patients using gradient recalled echo magnetic resonance imaging. On follow-up, data records of 16 studies were unavailable. Also, technically suboptimally 1 case was unfit for the study. So, net 199 studies were included. In 79 cases with confirmatory venography (n $=54)$, ultrasound ( $\mathrm{n}=16$, thigh veins only), or computed tomography ( $\mathrm{n}=9$, pelvic veins only), MRI was 97 percent sensitive, 95 percent specific, and 96 percent accurate. From the results, the authors concluded that MRI is skilled of precisely diagnosing acute DVT. ${ }^{10}$

In another study conducted by Carpenter JP et al, authors evaluated the effectiveness of MRI for the detection of DVT. Contrast venography and MRV was done in 85 patients. This was done from inferior vena cava for ruling out DVT. Duplex scanning was also done in 33 patients.

Comparison of blinded readings of these studies was done with the presence/absence and extent of DVT. As per findings of contrast venography, in 27 patients, DVT was documented.In 97 percent of the patients, results of the MRV and contrast venography were identical. In 98 percent of the patients, results of duplex scanning and contrast venography were identical. Detection of all the cases of DVTS by MRV and duplex scanning was done, which were identified by contrast venography. False positive results of MRV and duplex scanning were responsible for these discrepancies. Sensitivity and specificity of MRV was 100 percent and 96 percent respectively. From the results, they concluded that for the detection of DVT, MRV is an accurate noninvasive venographic technique. ${ }^{11}$

In 40 cases, acute deep vein thrombosis was present. 35 were confirmed on venography and the remaining 15 were confirmed on ultrasound. Sensitivity of MRI was found to be $96 \%$, while specificity of the MRI was found to be $98 \%$. The overall accuracy of MRI was found to be $97 \%$.

In another study conducted by Spritzer CE et al, authors assessed the gradient-recalled-echo (GRE) MR imaging changes caused by intraluminal thrombus of the lower extremities over time and established GRE MR imaging criteria to help distinguish acute from previous deep venous thrombosis. 10 subjects ( 4 females and 6 males) between the age group of 38 years to 76 years were included in their study. All the subjects underwent GRE MR imaging two to four time after the original diagnosis of deep venous thrombosis; eight also underwent confirmatory ultrasonography at that time. Mean follow-up for the patients of the present study was 3 months to one and a half year. Anticoagulants were used for treating all the patients. They calculated the evidence of thrombus, signal intensity characteristics, and MR imaging appearance were evaluated. Acute thrombosis was identified as an occlusion or prominent filling defect within the vessel. The luminal diameter of thrombosed veins was identical to or greater than that of a corresponding, unaffected vessel in each case. Acute thrombus signal intensity tended to be decreased initially and increase over time. Residual changes due to thrombosis included the web formation $(\mathrm{n}=3)$, luminal narrowing $(n=4)$, and wall thickening and/or slow flow $(n=5)$. Vessels in three patients reverted to normal. GRE MR imaging demonstrated progressive changes of venous thrombus over time. These criteria may help distinguish acute deep venous thrombosis from the residual changes of 
previous thrombosis. ${ }^{12}$

\section{CONCLUSION}

From the above results, the authors conclude that acute deep venous thrombosis cases can be accurately diagnosed by using gradient recalled echo acquisitions with MRI. However; further studies are recommended.

\section{REFERENCES}

1. Berger A. Magnetic resonance imaging. BMJ : British Medical Journal. 2002;324(7328):35.

2. Adalsteinsson E, Sullivan EV, Pfefferbaum A. Biochemical, functional and microstructural magnetic resonance imaging (MRI) In: Liu Y, Lovinger DM, editors. Methods in Alcohol-Related Neuroscience Research. Boca Raton, FL: CRC Press; 2002. pp. 345372.

3. Agartz I, Brag S, Franck J, et al. MR volumetry during acute alcohol withdrawal and abstinence: A descriptive study. Alcohol and Alcoholism. 2003;38(2):71-78.

4. Hillner BE, Philbrick JT, Becker DM. Optimal management of suspected lower-extremity deep vein thrombosis. An evaluation with cost assessment of 24 management strategies. Arch Intern Med 1992;152 (4):165-75.

5. Wells PS, Anderson DR, Bormanis J, et al. Value of assessment of pretest probability of deep-vein thrombosis in clinical management. Lancet 1997;350 (6):1795-8.

6. Kearon C, Julian JA, Newman TE, et al. Noninvasive diagnosis of deep vein thrombosis. Ann Intern Med 1998;128 (1):663-77.

7. Bates SM, Kearon C, Crowther MA, et al. A diagnostic strategy involving a quantitative latex D-dimer assay reliably excludes deep venous thrombosis. Ann Intern Med 2003;138 (5):787-94.

8. Wells PS, Lensing AWA, Davidson BL, et al. Accuracy of ultrasound for the diagnosis of deep venous thrombosis in asymptomatic patients after orthopedic surgery. A meta-analysis. Ann Intern Med 1995;122 (3):47-53.

9. Wells PS, Owen C, Doucette S, et al. Does this patient have deep vein thrombosis? JAMA 2006;295 (6):199207.

10. Spritzer CE, Norconk JJ Jr, Sostman HD, Coleman RE. Detection of deep venous thrombosis by magnetic resonance imaging. Chest. 1993;104(1):54-60.

11. Carpenter JP1, Holland GA, Baum RA, Owen RS, Carpenter JT, Cope C. Magnetic resonance venography for the detection of deep venous thrombosis: comparison with contrast venography and duplex Doppler ultrasonography. J Vasc Surg. 1993;18(5):734-41.

12. Spritzer CE1, Trotter P, Sostman HD. Deep venous thrombosis: gradient-recalled-echo MR imaging changes over time--experience in 10 patients. Radiology. 1998;208(3):631-9.

Source of Support: Nil; Conflict of Interest: None

Submitted: 08-10-2018; Accepted: 10-11-2018; Published online: 20-11-2018 